This item was submitted to Loughborough's Research Repository by the author.

Items in Figshare are protected by copyright, with all rights reserved, unless otherwise indicated.

\title{
The Mediterranean dietary pattern for optimising health and performance in competitive athletes: A narrative review
}

PLEASE CITE THE PUBLISHED VERSION

https://doi.org/10.1017/s0007114521003202

\section{PUBLISHER}

Cambridge University Press (CUP)

\section{VERSION}

AM (Accepted Manuscript)

\section{PUBLISHER STATEMENT}

This article has been published in a revised form in British Journal of Nutrition https://doi.org/10.1017/s0007114521003202. This version is published under a Creative Commons CC-BYNC-ND. No commercial re-distribution or re-use allowed. Derivative works cannot be distributed. ( The Authors.

\section{LICENCE}

CC BY-NC-ND 4.0

\section{REPOSITORY RECORD}

Griffiths, Alex, Jamie Matu, Eleanor Whyte, Petros Akin-Nibosun, Tom Clifford, Emma Stevenson, and Oliver M Shannon. 2021. "The Mediterranean Dietary Pattern for Optimising Health and Performance in Competitive Athletes: A Narrative Review”. Loughborough University. https://hdl.handle.net/2134/16406757.v1. 


\section{TITLE}

2 The Mediterranean dietary pattern for optimising health and performance in competitive 3 athletes: A narrative review

5 SHORT TITLE

6 Mediterranean diet in competitive athletes

7

$8 \quad$ AUTHORS

9 Alex Griffiths ${ }^{1}$, Jamie Matu ${ }^{1}$, Eleanor Whyte $^{2}$, Petros Akin-Nibosun ${ }^{3}$, Tom Clifford ${ }^{4}$, Emma 10 Stevenson $^{5}$, Oliver M Shannon ${ }^{5}$

\section{AFFILIATIONS}

$13{ }^{1}$ School of Clinical Applied Sciences, Leeds Beckett University, Leeds, LS1 3HE, United 14 Kingdom.

$15{ }^{2}$ South Tyneside and Sunderland NHS Foundation Trust, Sunderland Royal Hospital, Kayll 16 Road, SR47TP

$17{ }^{3}$ School of Medical Education, Newcastle University, Newcastle upon Tyne, NE2 4HH, 18 United Kingdom.

$19{ }^{4}$ School of Sport, Exercise and Health Sciences, Loughborough University, Loughborough, 20 United Kingdom.

215 Human Nutrition Research Centre, Population Health Sciences Institute, Newcastle University, Newcastle upon Tyne, NE2 4HH, United Kingdom. 
26 CORRESPONDING AUTHOR:

27 Dr. Oliver M Shannon

28 Email: Oliver.Shannon@Newcastle.ac.uk

29 Telephone: 01912081140

30 Address: Human Nutrition Research Centre, Population Health Sciences Institute, Newcastle

31 University, Newcastle upon Tyne, NE2 4HH, UK

32

33

KEY WORDS: Mediterranean diet; Health; Exercise performance; Vascular function;

34 Cognitive function; Oxidative stress

35

36

37

38

39

40

41

42

43

44

45

46

47

48

49

50

51

52

53 
ABSTRACT

55 Nutrition plays a key role in training for, and competing in, competitive sport, and is essential

56 for reducing risk of injury and illness, recovering and adapting between bouts of activity, and

57 enhancing performance. Consumption of a Mediterranean diet (MedDiet) has been

58 demonstrated to reduce risk of various non-communicable diseases and increase longevity.

59 Following the key principles of a MedDiet could also represent a useful framework for good

60 nutrition in competitive athletes under most circumstances, with potential benefits for health

61 and performance parameters. In this review, we discuss the potential effects of a MedDiet, or

62 individual foods and compounds readily available in this dietary pattern, on oxidative stress

63 and inflammation, injury and illness risk, vascular and cognitive function, and exercise

64 performance in competitive athletes. We also highlight potential modifications which could be made to the MedDiet (whilst otherwise adhering to the key principles of this dietary pattern) in accordance with contemporary sports nutrition practices, to maximise health and performance effects. In addition, we discuss potential directions for future research.

68

69 
The Mediterranean dietary pattern (MedDiet) reflects the traditional eating habits common among certain rural communities in the Mediterranean basin prior to the globalisation and Westernisation of food systems ${ }^{(1,2)}$. Salient characteristics of this diet include the high intake of fruits, vegetables, cereals, olive oil, legumes and tree nuts, moderate intake of fish and other seafood, and low intake of sugar sweetened foods, carbonated beverages, and red and processed meat. In addition, the traditional MedDiet includes a small-to-moderate intake of alcohol, which is typically ingested alongside meals. The potential health-promoting effects of this dietary pattern were first recognised in the 1950s as part of the Seven Countries Study, which was led by the celebrated public health scientist Ancel Keys ${ }^{(3)}$. Keys and colleagues identified dietary practices of individuals living in the Mediterranean area, including the use of olive oil as the principal fat, which were associated with a lower risk of cardiovascular disease (CVD) (3). A number of subsequent epidemiological studies have confirmed the protective effects of a MedDiet against CVD ${ }^{(4)}$, and have also identified a potential role of this dietary pattern in decreasing risk of metabolic (e.g. type II diabetes and metabolic syndrome) ${ }^{(5-7)}$ and neurodegenerative (e.g. Alzheimer's) ${ }^{(8,9)}$ diseases, alongside certain forms of cancer ${ }^{(10)}$. The beneficial effects of a MedDiet have also, more recently, been demonstrated in randomised controlled trials (RCTs), including the large-scale Prevención con Dieta Mediterránea (PREDIMED) trial ${ }^{(11,12)}$. PREDIMED demonstrated beneficial effects of a MedDiet to grow, with researchers continually seeking new applications for this healthy dietary pattern. Appropriate nutrition plays a key role in training for, and competing in, competitive sport, and is essential for reducing risk of injury and illness, recovering and adapting between bouts of 
activity, and enhancing performance ${ }^{(15,16)}$. Nutritional demands for competitive athletes often exceed those of their sedentary counterparts due to the prolonged amounts of time spent at an elevated metabolic rate ${ }^{(17,18)}$. Nevertheless, guidelines for healthy nutrition are likely to be similar for members of the public and athletes under most circumstances, with some potential exceptions where recommendations may diverge (for further details, see Optimising a MedDiet for Competitive athletes) ${ }^{(16)}$. Therefore, healthy dietary patterns such as the MedDiet, which are advocated for improving health in the general population ${ }^{(1)}$, may also play a role in the maintenance of optimal health and performance in athletic cohorts.

The applications of a MedDiet in a sporting context has received very little attention to date. To the authors knowledge, only one study has directly explored the potential performance enhancing effects of this dietary pattern ${ }^{(19)}$. Specifically, in a randomised cross-over study by Baker and colleagues ${ }^{(19)}, 11$ recreationally active participants consumed either a MedDiet or Western diet for 4 days, after which they completed a battery of exercise performance tests including a $5 \mathrm{~km}$ treadmill time-trial, a Wingate cycle test, a vertical jump test, and an assessment of grip strength via hand grip dynamometry. Remarkably, $5 \mathrm{~km}$ time-trial performance was $\sim 6 \%$ faster when participants consumed MedDiet compared with the Western diet, although other performance measures were no different between conditions. These findings require substantiation, but tentatively suggest a potential role of the MedDiet for improving (at least certain aspects of) sports performance. In a similar manner, numerous foods or compounds found in a MedDiet have also shown direct ergogenic effects, including nitrate-rich vegetables and vegetable juices ${ }^{(20-23)}$, n-3 fatty acids readily available in fish amongst other foods ${ }^{(24)}$, a variety of different fruits ${ }^{(25,26)}$, and certain types of nuts ${ }^{(27)}$. 
130 Building upon these preliminary findings, in the current article, we present the hypothesis that

131 following the key principles of a MedDiet could represent a useful framework for good nutrition in athletes under most circumstances with the potential to elicit physiological changes which positively impact athlete health and exercise performance. We also highlight potential modifications which could be made to this dietary pattern to comply with contemporary sports nutrition practices and identify potential directions for future investigation.

\section{THE MEDITTERRANEAN DIET AND TRADITIONAL SPORTS NUTRITION}

\section{GUIDELINES}

Current nutritional guidelines for athletes are primarily structured around macronutrient consumption ${ }^{(16)}$. In particular, the quantity and timing of carbohydrate, protein and fat consumption are manipulated to optimise substrate availability and training adaptations ${ }^{(16)}$.

Sport-specific nutritional recommendations typically state that endurance sports (e.g., prolonged cycling, running etc) are best supported by diets high in carbohydrate (e.g., 6-12 $\left.\mathrm{g} \cdot \mathrm{kg} \cdot \mathrm{d}^{-1}\right){ }^{(16,28)}$ especially in the days leading up to an endurance event ${ }^{(29)}$. Carbohydrate recommendations for endurance athletes therefore typically exceed those advocated for the general population ${ }^{(29)}$, although direct comparison is complicated by the fact that carbohydrate recommendations for the general population are usually expressed as a percentage of total energy requirement (i.e., 50\% total energy intake ${ }^{(30)}$ ) compared with sports-specific recommendations which are usually expressed in grams (per kilogram of body mass per day $\left[\mathrm{g} \cdot \mathrm{kg} \cdot \mathrm{d}^{-1}\right]{ }^{(16)}$. Recommended protein intakes for the general population are $0.75 \mathrm{~g} \cdot \mathrm{kg} \cdot \mathrm{d}^{-1}$ (UK Reference Nutrient Intake [RNI]) ${ }^{(31)}$. By contrast, current recommendations for dietary protein intake in athletes range from 1.2 to $2.0 \mathrm{~g} \cdot \mathrm{kg} \cdot \mathrm{d}^{-1}$, with values at the upper end of this range particularly relevant for strength-based athletes, individuals attempting to maintain lean 
mass during periods of energy deficit, or those undergoing high frequency/intensity training (16,32). Finally, dietary fat intake requirements for athletes have received little attention in the scientific literature, with recommendations typically focusing on carbohydrate and protein requirements ${ }^{(33)}$. However, based around current guidelines, fat intake recommendations for athletes largely align with those of the general population (i.e., $20-35 \%$ of total energy intake) $(16,31)$.

The MedDiet has been reported to provide approximately $43 \%$ energy from carbohydrate, $37 \%$ energy from fat and $15 \%$ from protein ${ }^{(34)}$. However, regional variations in the macronutrient distribution of this dietary pattern have been reported, and relative carbohydrate intakes as high as $\sim 59 \%$ of energy intake have been documented in Egypt ${ }^{(35)}$. When expressed relative to body mass, for a hypothetical $70 \mathrm{~kg}$ endurance athlete with a daily energy intake of $3500 \mathrm{kcal}, 43 \%$ and $59 \%$ energy from carbohydrate would translate into $\sim 5.4$ and $\sim 7.4 \mathrm{~g} \cdot \mathrm{kg} \cdot \mathrm{d}^{-1}$ carbohydrate. This suggests that carbohydrate intake in the traditional MedDiet may be sub-optimal for certain athlete groups (e.g., 6-12 $\mathrm{g} \cdot \mathrm{kg} \cdot \mathrm{d}^{-1}$ in endurance athletes) ${ }^{(16,28)}$, although certain permutations of this dietary pattern may more closely align with recommendations for athletes. Protein intake in an athletic population adhering to a MedDiet has been demonstrated to be as high as $\sim 1.5 \mathrm{~g} \cdot \mathrm{kg} \cdot \mathrm{d}^{-1(36)}$, which is comparable to traditional sport-specific recommendations, and exceeds the UK RNI ${ }^{(31)}$. In contrast, fat intakes are slighter higher in the MedDiet compared with healthy eating guidelines (37\% vs $20-35 \%$ total energy intake, respectively), although this is largely from monounsaturated fatty acids such as olive oil, which has been associated with numerous health benefits ${ }^{(2)}$. Therefore, overall, there are some differences in the macronutrient distribution of the MedDiet compared with both traditional healthy eating guidelines and sports nutrition recommendations. However, as discussed later, it is possible that the macronutrient distribution of the MedDiet could be manipulated on a day-by-day or 
session-by-session basis by altering the amounts of different foods which are typically consumed as part of this dietary pattern. This could help ensure athletes meet the macronutrient demands of different sporting situations, whilst otherwise retaining the benefits of consuming a MedDiet.

It is acknowledged that ensuring appropriate macronutrient intake is an important consideration for athletes. Nevertheless, focusing exclusively on the macronutrient profile of a diet may be an oversimplification which fails to account for the importance of micronutrients and other bioactive dietary compounds. To this end, current sport-specific and healthy eating guidelines also encourage consumption of a variety of foods (e.g., fruit, vegetables and dairy products) to avoid micronutrient deficiencies and support healthy physiological function ${ }^{(16)}$. The MedDiet includes many of the components associated with a traditional healthy diet consumed by athletes (e.g., high intake of fruit and vegetables). In addition, the MedDiet also advocates the liberal use of olive oil, high consumption of pulses/ legumes, regular intake of nuts and seeds, and small-to-moderate wine intake alongside meals ${ }^{(2)}$ Moreover, the fruit and vegetable content of a MedDiet may be higher than typically advocated in health eating guidelines (e.g., 3-6 portions of each per day $\left.{ }^{(37)}\right)$. The MedDiet is therefore rich in a constellation of different micronutrients and other bioactive dietary compounds (e.g., polyphenols including resveratrol and quercetin, inorganic nitrate, fibre, n-3 fatty acids) and following the key principles of this dietary pattern could be an effective way to maximise diet quality in athletes with potential health and performance benefits.

\section{POTENTIAL HEALTH AND PERFORMANCE BENEFITS OF A}


204 The MedDiet is a healthy, palatable, and cost-effective dietary pattern with a rich nutrient profile and widely documented health effects. In this section, we outline the rationale for why

a MedDiet could be relevant as a performance-enhancing and health-promoting diet in

207 competitive sporting populations.

\section{Oxidative stress of exercise}

210 High intensity exercise can increase formation of reactive oxygen species (ROS) and other free

211 radicals, with skeletal muscle representing the primary source of ROS during exercise ${ }^{(38)}$.

212 High levels of ROS can result in damage to macromolecular structures (e.g. DNA, lipids and 213 proteins) and both high and very low levels of ROS can inhibit muscle force production ${ }^{(39)}$.

214 Although often demonised as a negative by-product of exercise, ROS also play a crucial role 215 in adaptation to exercise via the activation of redox-sensitive signalling pathways, including 216 nuclear factor erythroid 2-related factor 2 (Nrf2), peroxisome proliferator-activated receptor 217 gamma coactivator 1-alpha (PGC-1 $\alpha$ ) and mammalian target of rapamycin (m-TOR) pathways $218^{(40-42)}$. Chronic exercise up-regulates the body's antioxidant defence system, which partly 219 offsets the acute increase in ROS during ${ }^{(39)}$, and in the days following, exercise ${ }^{(43)}$. However, controversy exists over whether competitive athletes should consume high levels of antioxidants, particularly via antioxidant supplements, to further attenuate exercise-induced oxidative stress (defined as a disruption to redox signalling and/or an increased ratio of oxidants to antioxidants) ${ }^{(39,44)}$.

Current research suggests that a hormetic response may exist, whereby low-to-moderate levels of exercise-induced ROS are beneficial for exercise performance and adaptation, whereas high levels of ROS may compromise muscle force production and attenuate the adaptive response 
not recommended in athletes (except in subjects with very low basal levels of antioxidants) ${ }^{(46)}$, given they may significantly alter redox state and impair exercise adaptations ${ }^{(41)}$. On the contrary, consumption of healthy dietary patterns which are naturally enriched in foods with antioxidant properties have been proposed as a more suitable strategy to mitigate high levels of oxidative stress without compromising physiological function or the adaptive response to exercise ${ }^{(47-49)}$. The differential effects of antioxidant supplements versus an antioxidant-rich diet may be related to the typically higher, and potentially detrimental, total dose of antioxidants provided in supplements ${ }^{(50)}$. Alternatively, the different effects of the two antioxidant vehicles could be related to the fact that antioxidant supplements typically only contain one single antioxidant, whereas plant-based foods contain a constellation of many hundreds/ thousands of phytochemicals which provide a network of different antioxidants ${ }^{(50)}$.

In contrast to the findings of studies reporting deleterious effects of vitamin $\mathrm{C}$ and $\mathrm{E}$ on adaptations during a high altitude training camp ${ }^{(51)}$, where production of ROS is typically elevated versus sea-level ${ }^{(52)}$, consumption of an antioxidant-rich food diet did not blunt adaptations to a 3-week altitude training camp $(2320 \mathrm{~m})$ in national team endurance athletes (50). On the contrary, haemoglobin concentration increased to a greater extent with the antioxidant-rich diet versus control. However, the significance of this finding is unclear and could simply reflect differences in participant hydration status (which was typically lower in control at baseline) given haemoglobin mass was comparable in both groups.

Key position statements from the ACSM and ISSN both advocate a well-chosen diet containing antioxidant rich foods such as fruits and vegetables ${ }^{(16,53)}$, which could help mitigate against high levels of oxidative stress in athletes. Benefits of consuming such a diet are demonstrated in a study by Watson et al. ${ }^{(54)}$, who contrasted exercise responses in trained athletes consuming 
a habitual diet with naturally high antioxidant levels compared with a diet with restricted intake of antioxidant-rich foods, which resulted in a threefold reduction in antioxidant intake. Ratings of perceived exertion were lower during exercise and $\mathrm{F}(2)$-isoprostane concentrations, a robust marker of lipid oxidation, were decreased post-exercise when following the high antioxidant diet. The authors concluded that individuals participating in regular, high-intensity exercise may require higher intake of antioxidant rich foods to protect against exercise-induced oxidative stress than sedentary individuals, which can be met through a healthy habitual diet without the need for dietary supplementation in most circumstances ${ }^{(54)}$.

The MedDiet contains a moderate-to-high intake of fruits and vegetables (e.g., 3-6 portions of each per day ${ }^{(37)}$ ), which is similar to (or slightly greater than) traditional guidelines for athletes. Uniquely, the MedDiet is also rich in olive oil and includes a modest intake of red wine, which may further increase the antioxidant potential of this diet. For example, olive oil phenolics such as hydroxytyrosol and oleuropein have been demonstrated to protect against high levels of oxidative stress and improve mitochondrial function in in vitro, ex vivo and animal model studies ${ }^{(55,56)}$. In the context of exercise, an interesting study by Musumeci et al. (57) demonstrated lower markers of oxidative stress (e.g., hydroperoxides and thiobarbituric acidreactive substances $[\mathrm{TBARS}])$ and increased markers of antioxidant defence (e.g., nonenzymatic antioxidant capacity and Hsp70 expression) following an exhaustive bout of exercise in male Sprague-Dawley rats consuming a habitual diet enriched with extra-virgin olive oil versus rats fed standard chow. Meanwhile, in humans, consumption of both wine (240 $\mathrm{ml} / \mathrm{d}$ or $\sim 1$ large glass) and the MedDiet as a whole have been demonstrated to decrease levels of oxidative DNA damage as indicated by lower concentrations of guanine oxidized metabolites, such as 8-oxo-2'-deoxyguanosine $(8-\mathrm{OHdG})$ in peripheral blood leukocytes ${ }^{(58)}$. Similar benefits, including increased total plasma antioxidant status, have also been observed with $300-400 \mathrm{ml} / \mathrm{d}$ 
279 wine for $\sim 2$ weeks ${ }^{(59-61)}$, although such high intakes may not be advocated in athletes (or other 280 populations) and more research into the possible antioxidant effects of lower doses of wine is warranted. Interestingly, consumption of $300 \mathrm{ml} / \mathrm{d}$ alcohol-free wine for 7 days has also been shown to increase activity of antioxidant enzymes such as glutathione reductase and superoxide dismutase ${ }^{(62)}$. Therefore, alcohol-free wine could be considered for consumption by athletes wishing to avoid alcohol intake whilst still benefiting from the antioxidant effects of this key MedDiet component.

Overall, these findings suggest that consumption of a healthy diet such as MedDiet which is naturally rich in foods with antioxidant properties could represent an effective strategy to help ameliorate high level of exercise-induced oxidative stress, without necessitating antioxidant supplements which may have a deleterious effect on exercise-induced adaptations ${ }^{(41)}$. Current evidence from the PREDIMED trial ${ }^{(63)}$ suggests that the MedDiet has superior antioxidant effects to a low-fat diet, which is often practiced by athletes. However, future research is warranted to determine whether the antioxidant effects of a MedDiet are comparable (or superior/ inferior) to other healthy diets which may advocated for athletes.

\section{Anti-inflammatory effects}

Exercise, particularly when it involves unaccustomed movements, eccentric muscle contractions, or is especially arduous in nature, can result in muscle damage which is associated with an increase in circulating and intramuscular markers of inflammation ${ }^{(64)}$. High levels of inflammation may slow the recovery process ${ }^{(65,66)}$, and strategies to attenuate exercise-induced inflammation may be valuable when the priority is to ensure rapid recovery between bouts of strenuous exercise (for example, between heats and finals or during a heavy period of regular competition) ${ }^{(67,68)}$. On the contrary, a drastic reduction in inflammation could attenuate 
304 exercise-induced training adaptations, including reduced skeletal muscle remodelling ${ }^{(69)}$. 305 Inflammation is also a key part of the response to injuries ${ }^{(15)}$, which are often a risk in athletes involved in high intensity, high volume training regimens ${ }^{(70)}$. Excess inflammation can slow the healing process although, considering the importance of inflammation in wound healing (71), major reductions in inflammation may be counterproductive for the healing response to some injuries ${ }^{(15)}$.

311 Adherence to a healthy dietary pattern could help support an appropriate inflammatory 312 response to exercise during regular training and competition, without resorting to specific anti313 inflammatory strategies (for example, non-steroidal anti-inflammatory drugs (NSAID) ${ }^{(72)}$ or 314 high-dose nutritional supplements $\left.{ }^{(15)}\right)$, except in situations where rapid recovery or mitigation of very high levels of inflammation are prioritised. Dietary manipulation rather than medicinal use is likely of benefit given the potential health risk for athletes consuming excessive NSAIDS. Associated side effects in exercising athletes include asthma exacerbation, gastrointestinal and renal side effects including acute kidney injury, hypertension, and other cardiovascular diseases ${ }^{(73)}$. The MedDiet may therefore represent an effective alternative to the use of NSAID in certain circumstances. Indeed, a number of studies have reported antiinflammatory effects of the MedDiet as a whole including reduced c-reactive protein (CRP), tumour necrosis factor- $\alpha$ (TNF- $\alpha$ ), and interleukin-6 (IL-6), which appear, in part, to be related to altered methylation of inflammation-related genes ${ }^{(74)}$ and downregulation of the nuclear factor kappa B $(\mathrm{NF}-\kappa \mathrm{B})$ pathway ${ }^{(75)}$. MedDiet components, particularly fish oils enriched in n-3 fatty acids ${ }^{(76)}$ and certain fruits ${ }^{(77,78)}$ have also been demonstrated to reduce high levels of inflammation following damaging exercise. The anti-inflammatory effects of the MedDiet have been demonstrated to help attenuate age-related inflammation (so called 'inflammaging') with attendant reductions in disease risk ${ }^{(2,79)}$, and could represent an effective strategy for 
helping support an appropriate inflammatory response during regular exercise training and competition which warrants direct exploration.

\section{Injury prevention}

In addition to the potential effects a MedDiet in controlling inflammation, key components of this dietary pattern could also be important for injury prevention or recovery via other mechanisms. For example, the MedDiet has been proposed to play a key role in maintenance of bone health ${ }^{(80)}$. Indeed, a recent systematic review and meta-analysis reported greater bone mineral density and reduced risk of fracture with higher versus lower MedDiet adherence ${ }^{(80)}$. Importantly, meta-regression analysis revealed a 5\% decrease in risk of hip fractures for each one unit increase in MedDiet score ${ }^{(80)}$. As the included studies were conducted in non-athletes, suitable caution needs to be applied when interpreting these findings. However, if present, similar effects could be valuable to competitive athletes in sports that have an increased risk of fractures (e.g., due to traumatic events) ${ }^{(81)}$, stress-fractures (e.g., due to cumulative, repetitive stress without adequate recovery) ${ }^{(82)}$ and osteoporosis (e.g., due to prolonged unloading in non-weight bearing sports) ${ }^{(83)}$.

The beneficial effects of a MedDiet on bone health could, in part, be related to the olive oil content of this dietary pattern. Indeed, extra virgin olive oil has been demonstrated to enhance bone mineral density in both rats and humans by increasing osteoblastogenesis and adipogenesis in mesenchymal stem cells ${ }^{\left({ }^{84}\right)}$. Additionally, intervention with a MedDiet supplemented with additional extra virgin olive oil for two years significantly increased serum osteocalcin, suggesting a potentially protective effect on bone ${ }^{(85)}$. The MedDiet has also been associated with higher circulating concentrations of $25(\mathrm{OH}) \mathrm{D}{ }^{(86)}$ and increased calcium absorption and retention, alongside lower calcium excretion, translating into higher bone 
354 turnover rates ${ }^{(87)}$ - factors which could further contribute towards the beneficial effects of this dietary pattern on bone health.

357 Similarly, n-3 fatty acids, available in fish and other seafood in the MedDiet, have also attracted notable attention in regards to recovery from injuries, particularly those which necessitate a period of immobility or reduced activity ${ }^{(15)}$. For example, fish oils - a known source of n-3

360 fatty acids - attenuated atrophy of the soleus muscle in rodents during hind limb immobilization compared with a corn oil diet control ${ }^{(88)}$. Mechanistically, n-3 fatty acids were shown to attenuate disturbances in the activation of the Akt pathway through E3 ubiquitin ligases and p70 s6 kinase ${ }^{(88)}$. Similarly, 8 weeks of n-3 fatty acid supplementation augmented the muscle protein fractional synthesis rate to hyperinsulinaemia-hyperaminoacidaemia, and increased phosphorylation of mTOR and p70 s6 kinase ${ }^{(89)}$.

Beneficial effects of n-3 fatty acids have also been proposed for traumatic brain injuries in athletes, particularly in sports such as rugby and American Football where these injuries are increasingly common. Murine model studies demonstrate a consistent benefit of n-3 fatty acids (particularly docosahexaenoic acid [DHA]) in the prevention and treatment of traumatic brain injury, which warrants study in humans ${ }^{(90,91)}$. By contrast, $\mathrm{n}-3$ fatty acid supplementation has been shown to impair wound healing in rats, which may be related to a supressed inflammatory response ${ }^{(92)}$.

Overall, the role of a MedDiet in injury prevention and/or recovery in humans warrants direct exploration, with specific consideration over whether effects may differ depending upon injury type. 


\section{Illness prevention}

380 Whether or not elite athletes are at a greater risk of infection and illness than the general 381 population remains unclear ${ }^{(93)}$. While regular exercise is undoubtedly beneficial for immune 382 function and reducing the incidence of illness and disease ${ }^{(94)}$, several studies suggest that 383 athletes are at greater risk of infection immediately after a strenuous period of training or competitive event ${ }^{(95,96)}$. The reasons are multifactorial and remain much disputed ${ }^{(94)}$, but suppression of immune cells, travel, fatigue, allergies, increased anxiety, sleep disruption, and poor diet could all play a role. Regardless of the precise reasons, the prevalence of illness in elite athletes, most of which are upper respiratory in origin, have been reported to be as high as $7 \%$ during competition ${ }^{(97,98)}$. The resulting increase in the number of training sessions and competitions that are either missed or performed sub-optimally can significantly hinder an athlete's chances of success throughout their career ${ }^{(99)}$. Therefore, maintaining a healthy immune system capable of mounting effective response to viruses and pathogens is vitally important for competitive athletes. Diet has a profound influence on immune cells ${ }^{(100)}$, and consuming a healthy diet may play a key role in maintaining a healthy immune system.

Direct evidence for a beneficial effect of the MedDiet as a whole on illness/ infection risk is very limited, although the findings from available studies are promising. One observational study of over 30,000 adults reported $26 \%$ lower risk of sepsis with high versus low MedDiet adherence ${ }^{(101)}$. Another study demonstrated that transitioning towards a MedDiet reduced number of catarrhal episodes, degree of intensity of colds, and emergency and hospital admissions in children aged 1-5 years with recurring colds and frequency inflammatory complications ${ }^{(102)}$. More promising evidence exists to show that key components of the MedDiet may play a role in maintaining a well-functioning immune system, which requires direct substantiation in athletes. 
404 It has been suggested that low intakes of the n-3 fatty acids, available in fish and other sources 405 in the MedDiet but less frequently consumed as part of the classic Western diet, may impair 406 the resolution of inflammation after exposure to a stress or infection ${ }^{(103,104)}$. This could be 407 linked to ineffective activation of the specialized pro-resolving mediators that are metabolised 408 from DHA and eicosapentaenoic acid (EPA) and play fundamental roles in the cessation of an immune response ${ }^{(104)}$. By contrast, increasing intake of the n-3 fatty acids EPA and DHA has been shown to enhance some aspects of immune function relevant to infections risk following exercise. For example, 6 weeks consumption of krill oil ( $2 \mathrm{~g}$ /day) increased the cytotoxic activity of natural killer cells (which destroy virally infected cells) 3 hours following high intensity exercise ${ }^{(105)}$. Both this study, and another that provided $3 \mathrm{~g} /$ day of fish oil for 6 weeks (106), found that n-3 fatty acids augmented post-exercise increases in PBMC interleukin-2 production, which suggests an enhanced T-helper 1 (Th1) cytokine response and possible antiviral benefit. Although further research is needed to determine the optimal dose of n-3 fatty acids to elicit such effects, and their clinical significance, these findings suggest that a diet emphasizing adequate intake of n-3 fatty acids could benefit athletes' immune function. Indeed, recent recommendations suggest that consumption of $250 \mathrm{mg} / \mathrm{d}$ EPA and DHA may help optimise immune function ${ }^{(103)}$. This amount is easily achievable with a MedDiet, which typically contains $\geq 3 \times 100-150$ g servings of fish or 200 g servings of other seafood per week EPA and DHA, which would meet the entire weekly requirement for these n-3 fatty acids ${ }^{(107)}$.

Various (poly)phenol compounds, also abundant in the MedDiet ${ }^{(108)}$, may play a role in maintaining a well-functioning immune system and preventing infection. Indeed, several (poly)phenols, including resveratrol from red wine, have been shown to not only modulate aspects of the immune system, but to also exert anti-bacterial and anti-viral effects ${ }^{(109,110)}$. 
429 Such effects have led some scientists to argue that (poly)phenols could be used as an adjuvant

430 therapy for the highly contagious COVID-19 ${ }^{(11)}$. Although most studies showing anti-viral

431 effects of (poly)phenols are in vitro, there is some evidence of similar effects in vivo (112,113)

432 and ex vivo ${ }^{(113,114)}$ in athletic populations.

434 Few studies have examined whether (poly)phenols can reduce infections in athletes, although there is some evidence that the flavonoid, quercetin, may reduce upper respiratory infection (URTI) symptoms (e.g., runny nose, coughing) after strenuous exercise ${ }^{(115)}$. For example,

Neiman et al. ${ }^{(115)}$ found that $1 \mathrm{~g}$ /day of quercetin reduced URTI symptoms in the 2 -week period following 3 days of intense cycling exercise. In addition, 5 weeks intake of a (poly)phenol-rich non-alcoholic beer (predominantly catechins and phenolic acids) decreased URTI incidence by over 3-fold in the 2 weeks after the Munich marathon in healthy male runners ${ }^{(116)}$. Interestingly, quercetin was initially proposed to reduce URTI symptoms by bolstering the immune system and/or attenuating oxidative stress, yet many of the in vivo studies have not observed changes in either following exercise, suggesting that anti-viral effects might provide

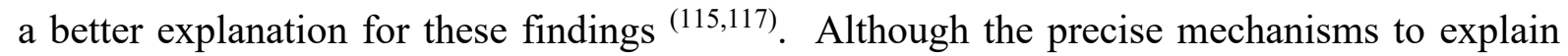
how quercetin and other (poly)phenols may reduce URTI symptoms is not well-understood, these studies provide tentative support for a role of (poly)phenols in reducing infection rates in athletes.

As recently highlighted in a consensus statement on immuno-nutrition and exercise, future research needs to determine the minimum dose required to reduce URTI symptoms, and whether increasing dietary intake of (poly)phenols can elicit similar effects to high doses of individual (poly)phenols ${ }^{(118)}$. Against this background, it is difficult to say whether the (poly)phenol content (and content of specific (poly)phenols such as quercetin) of a MedDiet, 
or other healthy diets which may be advocated for athletes, would be sufficient to reduce incidence of illness and infection. For example, achieving the $1 \mathrm{~g} / \mathrm{d}$ quercetin intake shown to benefit immune function in the study by Neiman et al., ${ }^{(115)}$ is implausible via a typical healthy diet, even one containing an abundance of quercetin-rich foods such as onions $(\sim 45 \mathrm{mg}$ quercetin/ 100g), spinach ( $\sim 27 \mathrm{mg}$ quercetin/ 100g), lettuce ( $\sim 15 \mathrm{mg}$ quercetin/ 100g), and red wine $(\sim 3 \mathrm{mg} \text { quercetin/100 ml })^{(119)}$. Nevertheless, some observational evidence suggests that modest intakes of red and white wine (1-7 glasses/ week) are associated with a $34 \%$ and 33\% reduced risk of common cold compared with 0 glasses ${ }^{(120)}$, respectively, suggesting that a small-to-moderate intake of wine, consistent with practices in the MedDiet, could still reduce risk of certain illnesses/ infections.

Overall, the evidence presented in this section tentatively suggests that consumption of key help reduce risk of illness/ infection. Further research is needed to substantiate these preliminary findings in athletes (and non-athletes), with a particular focus on whether the amount of bioactive compounds, especially (poly)phenols, consumed as part of the MedDiet are sufficient to enhance immune function without the need for additional dietary supplementation. As noted previously, is also necessary to determine whether a MedDiet has greater availability of immunomodulating compounds such as (poly)phenols, and subsequently greater effects on illness/ infection risk, compared with other healthy diets which may be advocated for athletes.

\section{Vascular function}

477 Exercise is known to protect against CVD, with an efficacy comparable to that of many 478 pharmacological interventions ${ }^{(121)}$. However, somewhat paradoxically, recent evidence 
suggests that Masters athletes who have engaged in lifelong competitive exercise may actually have greater risk of atherosclerotic plaque formation compared with sedentary controls ${ }^{(122,123)}$. For example, Merghani et al. ${ }^{(122)}$ reported presence of atherosclerotic plaques in $44 \%$ of Masters athletes compared with only $22 \%$ of sedentary controls. Similarly, Schwartz et al. ${ }^{(123)}$ reported increased total, calcified, and non-calcified plaque volumes in male marathon runners who had completed $\geq 1$ marathon/year for 25 consecutive years versus sedentary controls. The clinical significance of these plaques remains to be elucidated, and it is unclear whether they represent a response to chronic high-intensity exercise or accompanying dietary and other lifestyle factors. Particularly relevant to Masters athletes, Fernandez et al ${ }^{(124)}$ demonstrated that moderate-to-high intensity training enhances the positive effects of the MedDiet on the regenerative capacity of the endothelium in older, albeit sedentary individuals with metabolic syndrome. Thus, the cardio-protective effects of the MedDiet may be potentiated in individuals partaking in regular physical activity (i.e., athletes). Nevertheless, given the paucity of research in this area and the well documented cardiovascular benefits of a MedDiet ${ }^{(12,79,125)}$, the role of this dietary pattern in mitigating formation of atherosclerotic plaques and maintaining cardiovascular health in Masters athletes is worthy of further investigation.

\section{Cognitive function}

497 Cognitive function is a key aspect of sports performance, with athletes across a range of sporting scenarios (e.g., combat sports, endurance sports, invasion games etc) required to make rapid and appropriate tactical decisions to maximise their chance of success ${ }^{(126)}$. Acute exercise can both positively and negatively impact cognitive performance, depending upon exercise intensity and the nature of the cognitive task ${ }^{(127)}$. Nevertheless, strategies to optimise cognitive performance during sport are highly desirable, and nutritional interventions are acknowledged as a potential means of boosting cognitive performance during exercise ${ }^{(128)}$. 
504 Numerous observational studies have demonstrated beneficial associations between higher

505 MedDiet adherence and cognitive function across a range of cognitive domains ${ }^{(37,129,130)}$.

506 Similarly, intervention with a MedDiet has been shown to enhance cognitive performance in 507 some ${ }^{(131-133)}$, but not all ${ }^{(134)}$, studies, with the difference in findings between investigations 508 potentially reflecting differences in the cognitive testing battery employed, the participant 509 cohort, or the specific construction of the MedDiet administered to participants ${ }^{(134)}$. Some 510 evidence also exists to show that extracts from key MedDiet components such as vegetables $511{ }^{(135,136)}$ and fruits ${ }^{(137)}$ can directly benefit cognitive performance during exercise in young 512 athletic cohorts. Notably, studies by Thompson et al. ${ }^{(135,136)}$ have demonstrated beneficial 513 effects of beetroot juice, which provides inorganic nitrate in an amount achievable through a 514 plant-based diet such as the MedDiet ${ }^{(138)}$, on cognitive performance during high-intensity exercise. However, evidence is lacking for an effect of the MedDiet as a whole on cognitive performance during exercise tasks, such that we cannot necessarily infer a beneficial effect of this dietary pattern on cognition in a sporting context. This is especially so given the fact that most competitive athletes are young and healthy, whereas the majority of studies exploring effects of the MedDiet on cognition have included older participants with existing comorbidities ${ }^{(129)}$. Indeed, to the authors knowledge, only one study has directly explored the effects of a MedDiet intervention on cognitive performance in younger individuals (mean age: 21 years), with inconsistent effects occurring ${ }^{(139)}$. Similarly, it is possible that studies on isolated compounds in the MedDiet may not necessarily reflect effects conferred by this diet as a whole. Therefore, more direct research is needed before the MedDiet can be recommended to athletes as a potential strategy to improve cognitive performance. 
530 In this article, we have presented evidence to suggest that following the key principles of a

531 MedDiet may represent a useful model of healthy eating for competitive athletes under most

532 circumstances. Nevertheless, there are certain situations where strict adherence to this dietary

533 pattern may not be optimal for athlete health and/or performance. In the following section, we

534 provide some examples of where modifications to the MedDiet may be advocated in

535 accordance with contemporary sports nutrition practices.

536

537 Macronutrient distribution and fuelling for the work required

538 As previously discussed, sport-specific nutritional recommendations support high 539 carbohydrate intake $\left(6-12 \mathrm{~g} \cdot \mathrm{kg} \cdot \mathrm{d}^{-1}\right)^{(16,28)}$ for endurance athletes in training and competition.

540 This contrasts with the moderate $\sim 43 \%$ energy provision from carbohydrates in the MedDiet

541 (34). For example, a 70kg endurance athlete with a daily energy intake of $3500 \mathrm{kcal}$, including $43 \%$ of energy provided by carbohydrate, would consume $1505 \mathrm{kcal}$ or $\sim 376 \mathrm{~g} \cdot \mathrm{d}^{-1}$ via carbohydrate. This equates to $\sim 5.4 \mathrm{~g} \cdot \mathrm{kg} \cdot \mathrm{d}^{-1}$ carbohydrate, and falls short of the lower end of carbohydrate recommendations for this population ${ }^{(16)}$. It may therefore be necessary for endurance athletes consuming a MedDiet to augment their carbohydrate intake to ensure optimal glycogen storage and availability prior to training and competition ${ }^{(29)}$. This could be achieved by prioritising intake of higher carbohydrate foods such as grains and starchy vegetables, without deviating from the overall healthy eating principles of this dietary pattern.

549 This may necessitate a corresponding decrease in the consumption of fat prior to training and competition, to avoid excess energy intake and ensure athletes are able to meet carbohydrate requirements for exercise. Interestingly, the high carbohydrate intakes observed by some countries within the Mediterranean Basin (e.g. 59\% of energy derived from carbohydrate intake 
553 in Egypt) ${ }^{(35)}$ suggest that modest increases in carbohydrate intake may not result in the loss of any associated health benefits, although direct research is required on this topic.

A more nuanced approach may involve following the recently proposed 'fuelling for the work required' paradigm ${ }^{(140)}$. The central tenet of this concept is that athletes could benefit from adjusting carbohydrate intake levels in accordance with the demands of upcoming training sessions, in order to obtain benefits associated with periodically training with low glycogen availability (e.g. increased cell signalling, gene expression and oxidative enzyme activity), without compromising absolute training intensity ${ }^{(140)}$. Athletes hoping to benefit from this periodized nutritional approach could adjust the content of higher carbohydrate foods (in a diet otherwise based on the principles of a MedDiet) on a day-by-day or session-by-session basis, to ensure exercise is conducted with the optimal muscle glycogen concentrations necessary to meet the training demands. Such an approach would require careful planning by the athlete, in coordination with nutritional support staff and the coaching team.

Dietary protein recommendations for endurance athletes typically range from 1.2 to $1.5 \mathrm{~g} \cdot \mathrm{kg} \cdot \mathrm{d}^{-}$

$569{ }^{1}$, whereas recommendations for strength-based athletes are $\sim 1.6$ to $2.0 \mathrm{~g} \cdot \mathrm{kg} \cdot \mathrm{d}^{-}(16,141)$. Protein intakes of $\sim 1.5 \mathrm{~g} \cdot \mathrm{kg} \cdot \mathrm{d}^{-1}$ have been observed within an athletic population adhering to a MedDiet ${ }^{(36)}$, which falls within current guidelines for endurance athletes, but may be insufficient to maximise adaptions for strength-based athletes. An individualised approach is likely necessary to determine if incorporation of additional protein to a MedDiet is required to support metabolic adaptation, and skeletal muscle repair and remodelling. This is likely particular pertinent for those individuals whose protein needs may be $>2 \mathrm{~g} \cdot \mathrm{kg} \cdot \mathrm{d}^{-1}$ (e.g., for those attempting to maintain fat-free mass in an energy deficit $\left.{ }^{(141)}\right)$. 
Optimisation of protein intake does not simply relate to the amount of protein ingested, but also relates the factors such as the timing and type of protein consumed ${ }^{(142)}$. Although debate continues around the optimal timing of protein intake, some evidence indicates that consumption of protein proximal to exercise (either before or after intensive training) may help augment muscle protein synthesis and exercise-induced adaptations compared with a similar intake of this macronutrient at other times of the day ${ }^{(142)}$. Adjusting the timing of protein-rich meals to coincide with exercise may therefore help boost training adaptations ${ }^{(142)}$. Given evidence from both in vivo and in vitro studies suggests that the amino acid leucine may represent an effective 'trigger' for muscle anabolism, consumption of foods rich in this amino acid may also be particularly important for maximising muscle protein synthesis ${ }^{(32,143)}$. Conveniently, several foods found in the MedDiet appear to be rich in leucine, including certain fish, white meat, and legumes/ pulses.

\section{Periodic consumption of sugar-sweetened beverages}

The MedDiet typically comprises a low intake of sugar-sweetened beverages ${ }^{(37,144)}$. The omission of such beverages could contribute to the salutary effects of this dietary pattern, given negative associations reported between sugar-sweetened drinks and obesity ${ }^{(145)}$, diabetes ${ }^{(146)}$ and coronary heart disease ${ }^{(147)}$. By contrast, consumption of carbohydrate beverages pre-, during and post-exercise are generally accepted to augment performance ${ }^{(16,148,149)}$ and recovery (150). This is particularly pertinent for endurance athletes seeking to augment exogenous carbohydrate oxidation rates and/or resynthesise glycogen stores ${ }^{(151,152)}$, thus facilitating high intensity exercise bouts ${ }^{(153)}$. As such, it may be beneficial for athletes otherwise following the principles of a MedDiet to occasionally consume carbohydrate beverages during intensive training periods and competition, given the ergogenic properties of this nutritional strategy. In addition to supporting performance and recovery, a high carbohydrate intake has also been 
shown to support immune function. Indeed, high carbohydrate availability before prolonged

604

605

606

607

608

609

610

611

612

613

614

615

616

617

618

619 exercise ( $\geq 60 \mathrm{~min}$ ), followed by high rates of ingestion during ( $\geq 30 \mathrm{~g} / \mathrm{h}$ ), attenuates changes in stress hormones (cortisol, adrenaline) and various immune cells, including cytokines, leukocytes, and lymphocytes ${ }^{(154)}$. However, there is presently little evidence that this translates into improved clinical outcomes (e.g., reduced infection rates).

\section{Alcohol intake}

One of the key factors which distinguishes a MedDiet from other healthy dietary patterns is that it includes a small-to-moderate intake of alcohol (typically red wine), which is usually consumed alongside meals rather than in isolation ${ }^{(1)}$. Whether athletes following a MedDiet should also consume the alcohol component of this diet, or whether they may be advised to completely or selectively (i.e., immediately before or after exercise) omit this component, will be briefly discussed in this section.

Current evidence indicates that pre-exercise alcohol consumption has a small ergolytic effect on performance during prolonged, endurance exercise, whereas strength is typically unaffected by alcohol intake, even at high doses ${ }^{(155)}$. By contrast, pre-exercise alcohol intake is prohibited in certain sports (e.g., archery) given perceived performance advantages. When consumed immediately post-exercise, most aspects of recovery are unlikely to be negatively impacted by alcohol consumption with a dose $<0.5 \mathrm{~g} \cdot \mathrm{kg}^{-1}$ body mass, which is equivalent to $35 \mathrm{~g}$ for a $70 \mathrm{~kg}$ individual or roughly half a bottle of wine depending upon strength ${ }^{(155)}$. This suggests that consuming modest amounts of alcohol, such as a small glass of red wine with an evening meal following the completion of all daily training, in accordance with the dietary practices of the MedDiet, are unlikely to have negative performance implications for athletes under normal circumstances. By contrast, current recommendations are to avoid alcohol consumption during 
recovery from soft tissue injuries, as small alterations in protein synthesis, tissue blood flow and immune function may hinder recovery ${ }^{(155)}$.

When considering a) the lack of evidence to support a positive effect of alcohol on strength/ endurance exercise performance, b) the fact that pre-exercise alcohol intake is prohibited in sports where it is considered to be potentially ergogenic such as archery, and c) potential risks

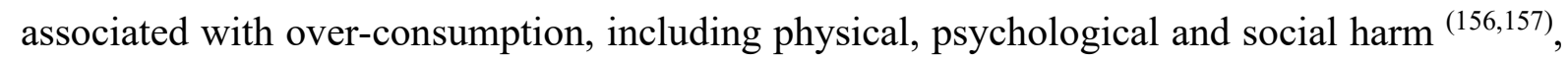
it seems unwise to actively encourage alcohol intake in athletes who currently abstain. Moreover, consuming alcohol during recovery from a soft-tissue injury should be avoided to minimise recovery impacts ${ }^{(155)}$. However, it is possible that there could be small benefits of adjusting drinking habits towards those common with a MedDiet in individuals who already consume alcohol. Specifically, consuming small amounts of red wine in preference to spirits or other alcohol could confer benefits linked to the phenolic compounds in wine ${ }^{(158)}$. Moreover, consuming small amounts of wine in the context of a meal may be preferable to alcohol consumption alone, as beneficial synergistic interactions may occur between wine phenolics and other dietary components ${ }^{(159)}$. Nevertheless, this requires direct investigation, and athletes and support staff should carefully consider the costs and perceived benefits of alcohol consumption. As noted previously, one option for athletes wishing to follow the common drinking habits of a MedDiet whilst minimising alcohol intake could be to consume alcohol-free wine, which appears to retain at least some of the benefits associated with wine intake including antioxidant effects ${ }^{(62)}$.

\section{Sodium intake}

The MedDiet is typically low in sodium ${ }^{(160)}$, a characteristic which may contribute towards the beneficial effects of this dietary pattern on blood pressure ${ }^{(125)}$, endothelial function ${ }^{(79)}$, and 
cardiovascular risk $^{(12)}$. Nevertheless, during certain sporting situations - especially prolonged, intensive exercise in the heat in unacclimatised individuals - increased sodium intake may be temporarily advocated in order to mitigate risk of hyponatremia ${ }^{(161)}$, preserve muscle contractility, and allow more effective restoration of fluid balance post-exercise ${ }^{(162)}$.

657

\section{Fibre intake}

The high fibre content of a MedDiet may contribute towards reported beneficial effects of this dietary pattern on composition and metabolism of the gut microbiota ${ }^{(163,164)}$ and reduced risk of certain cancers (especially of the digestive tract) ${ }^{(165)}$. Fibre is also acknowledged as playing a key role in maintenance of good health in athletes ${ }^{(166)}$. Nevertheless, high intake of fibre before competition has been associated with the development of negative GI symptoms. For example, Rehrer et al. ${ }^{(167)}$ identified high fibre intake in the pre-race meal to be a risk factor for GI complaints, especially intestinal cramps, in athletes competing in a half Ironman triathlon event. Current guidelines therefore advocate the avoidance of fibre in the day or days prior to competition to minimise risk of GI upset, but with adequate fibre in the habitual diet during training in order to optimise health ${ }^{(166)}$.

ADHERENCE TO THE MEDITERRANEAN DIET AND TRADITIONAL SPORTS NUTRITION RECOMMENDATIONS IN COMPETITIVE ATHLETES

Given the potential health and performance benefits of the MedDiet for athletes, it is relevant to explore current athlete adherence to this dietary pattern, which will help identify whether specific MedDiet interventions could be warranted in this cohort. For reference and comparison, we also start by providing a brief outline of athlete adherence to typical sports nutrition recommendations which, as outlined below, is often sub-optimal. 
678 Adherence to traditional sports nutrition recommendations varies substantially between 679 athletes and sports, although current evidence suggests that many athletes fail to achieve

680

681

682

684

685

686 traditional sports nutrition recommendations during training and competition, especially in regards to carbohydrate intake levels ${ }^{(28,168)}$. For example, one study reported that $\sim 81 \%$ of endurance athlete consumed lower than recommended quantities of carbohydrate in their diet (169). With regards to protein intake, in one study of over 500 well-trained Dutch athletes, average protein intake levels were 1.5 and $1.4 \mathrm{~g} \cdot \mathrm{kg} \cdot \mathrm{d}^{-1}$ in men and women, respectively, which compares favourably against current recommended intake values of 1.2 to $2.0 \mathrm{~g} \cdot \mathrm{kg} \cdot \mathrm{d}^{-1}$. Nevertheless, the range of protein intake was highly varied (men: 0.5 to $2.7 \mathrm{~g} \cdot \mathrm{kg} \cdot \mathrm{d}^{-1}$; women: 0.4 to $\left.3.6 \mathrm{~g} \cdot \mathrm{kg} \cdot \mathrm{d}^{-1}\right)$, such that many individuals were outside of the optimal range for intake of this macronutrient ${ }^{(170)}$. Finally, fat intake recommendations for athletes of $20-35 \%$ total energy intake appear to be achievable in most circumstances ${ }^{(33,171)}$, although some athletes may be at risk of under-consuming fat, especially in endurance, weight category, and aesthetic sports (172,173). Female athletes also demonstrated insufficient intake of several micronutrients including B vitamins, potassium, calcium, phosphorus, iron, manganese and zinc ${ }^{(169,174)}$. An inability to meet relevant recommendations may have deleterious effects on performance and increase the risk of injury and illness ${ }^{(16,175)}$. Strategies to understand barriers and enablers to nutritional adherence in high performance sport is receiving increasing attention in the literature ${ }^{(168)}$. As a palatable, cost effective dietary strategy, it is possible that the MedDiet may provide one option to help individuals achieve traditional sport-specific recommendations whilst also benefiting from the inclusion of foods and dietary compounds with additional health/ performance effects.

To date, few studies have attempted to quantify level of adherence to the MedDiet in athletes, with mixed results emerging ${ }^{(176-180)}$. Crucially, these studies have been exclusively conducted 
in Spain - a country in which MedDiet adherence is traditionally high ${ }^{(1)}$, but may be decreasing due to Westernisation of the diet ${ }^{(181)}$. Therefore, findings are unlikely to be indicative of MedDiet adherence levels in other populations.

A large cross-sectional study by Muros and Zabala ${ }^{(176)}$ demonstrated modest adherence to the MedDiet in 4037 Spanish cyclists and triathletes, as determined by scores on the 14-point Mediterranean diet adherence screener (MEDAS score: 7.64) ${ }^{(176)}$. The MEDAS scores reported by Muros and Zabala ${ }^{(176)}$ are marginally higher than reported recently in non-athletic Spanish cohorts (MEDAS score: 6.34), although both scores are lower than the typical MEDAS threshold used to define high MedDiet adherence (i.e., $>9$ points) ${ }^{(181)}$. A small study of 12 Spanish female Futsal players also reported low and moderate MedDiet adherence in $\sim 58 \%$ and $\sim 42 \%$ of athletes, respectively ${ }^{(177)}$. In contrast, in a cross-sectional study which evaluated MedDiet adherence in Spanish amateur cyclists (male $n=701$, female $n=84$ ), and inactive individuals (male $\mathrm{n}=307$, female $\mathrm{n}=411$ ), $48 \%$ of male cyclists reported high adherence to the MedDiet, compared with just $22 \%$ of male inactive individuals ${ }^{(178)}$. This trend was replicated in females, with $57 \%$ of female cyclists reporting high adherence to the MedDiet compared with $36 \%$ of their inactive counterparts ${ }^{(178)}$. Finally, in a study of 90 Spanish kayakers ${ }^{(179)}$, only one participant had low MedDiet adherence, whilst 38 and 51 individuals reported medium and high MedDiet adherence, respectively. Nevertheless, low consumption of nuts (a key MedDiet component) and high consumption of sweets and commercially made pastries (typically consumed in low amounts as part of the MedDiet) was reported.

Overall, current evidence tentatively supports the notion that athletic individuals exhibit marginally higher MedDiet adherence levels compared with inactive individuals ${ }^{(176,178)}$. Furthermore, it appears that athletic women have higher adherence to the MedDiet than men 
(178). This may be related to less frequent fast food consumption during the competitive season

${ }^{(182)}$, as well as greater nutritional knowledge and education in athletic women compared with men ${ }^{(183,184)}$. Additional large-scale studies in other cohorts are needed to better understand current levels of adherence to the MedDiet in both Mediterranean and non-Mediterranean countries. Moreover, larger, more diverse samples of athletes are needed in future research to explore potential differences between individuals depending upon their sex, ability level, sport, and age. The MedDiet may provide a prudent dietary pattern for the health and performance of athletes worldwide, and a better understanding of current levels of adherence to this dietary pattern will be important in determining the need for potential MedDiet interventions in athletic cohorts.

\section{CONCLUSIONS AND FUTURE DIRECTIONS}

In this review, we have provided preliminary evidence to suggest that the MedDiet could represent a useful model of healthy eating in competitive athletes under most circumstances, with the potential to help optimise certain aspects of health and performance. We have also identified certain areas where, in accordance with contemporary sports nutrition practices, subtle modifications could be made to the MedDiet (whilst otherwise adhering to the key principles of this dietary pattern) to maximise potential ergogenic effects.

Going forward, several questions remain unanswered and may represent useful directions for future research. For example, at present, little is known about current levels of adherence to the MedDiet, and potential barriers to adopting this dietary pattern in athletes. However, such information is important as it could help identify individuals who may be suitable for future MedDiet interventions, and help optimise the design of studies hoping to increase adherence to this dietary pattern in athletes. The effect of the MedDiet on appetite/satiety also requires 
consideration, as the satiating effect of the MedDiet could provide challenges to some athletes in ensuring they consume sufficient caloric intake. In addition, numerous studies suggest that consumption of key foods or compounds available in the MedDiet could enhance health and performance in athletes. However, very few studies have focused on the potential effects of a MedDiet as a whole in athletic cohorts. Indeed, as part of this review, we identified only one study by Baker and colleagues ${ }^{(19)}$ which directly explored effects of the MedDiet on exercise performance. This study involved a relatively short-term (4-days) intervention period and included a small set of exercise performance measures ${ }^{(19)}$. Further research is therefore needed to understand whether beneficial performance effects of a MedDiet occur immediately upon transitioning to this dietary pattern or whether they require a certain amount of time to fully manifest. Additional studies exploring the performance effects of a MedDiet in different cohorts, and employing a range of exercise tests, are also warranted. Given the MedDiet includes (and excludes) a constellation of different foods, and no uniform definition exists for the specific constituents of this dietary pattern, it is possible that the construction of a MedDiet (i.e. the relative amounts of different foods included and excluded from this dietary pattern) could also influence the health and performance effects observed. Therefore, further research is warranted to identify whether specific permutations of the MedDiet could be especially effective in optimising athlete health and performance.

In summary, preliminary evidence suggests that consumption of a MedDiet, and its individual components, could play a role in optimising certain aspects of health and performance in competitive athletes. Further research in this area could produce fruitful results which are of benefits to athletes, coaches and nutritional practitioners, and is strongly encouraged. 
$779 \quad$ N/A

780

\section{$781 \quad$ Financial support}

782 This research was supported by a grant from the UK Nutrition Research Partnership (UK NRP), 783 an initiative supported by the Medical Research Council (MRC), Biotechnology and Biological 784 Sciences Research Council (BBSRC) and the National Institute for Health Research (NIHR) 785 (E.S., MR/T001852/1).

786

787 Conflict of interest

788 None.

789

\section{$790 \quad$ Authorship}

791 This review was conceived and designed by OMS. The review was written by AG, JM, EW, 792 PA-N, TC, ES and OMS. PA-N produced the graphical abstract. All authors have read and 793 approved the final version of the manuscript.

794

795 


\section{REFERENCES}

797 1. Bach-Faig A, Berry EM, Lairon D et al. (2011) Mediterranean diet pyramid today. Science and cultural updates. Public Health Nutr 14, 2274-2284.

2. Shannon OM, Ashor AW, Scialo F et al. (2021) Mediterranean diet and the hallmarks of ageing. Eur J Clin Nutr. Published online: $29^{\text {th }}$ January 2021. doi: 10.1038/s41430020-00841-X.

3. Keys A, Menotti A, Karvonen MJ et al. (1986) The diet and 15-year death rate in the seven countries study. Am J Epidemiol 124, 903-915.

4. Martínez-González Miguel A., Gea Alfredo, \& Ruiz-Canela Miguel (2019) The Mediterranean Diet and Cardiovascular Health. Circ Res 124, 779-798.

5. Assaf-Balut C, García de la Torre N, Duran A et al. (2019) A Mediterranean diet with an enhanced consumption of extra virgin olive oll and pistachios improves pregnancy outcomes in women without gestational diabetes mellitus: A sub-analysis of the St. Carlos Gestational Diabetes Mellitus Prevention Study. Ann Nutr Metab 74, 69-79.

6. Esposito K, Maiorino MI, Bellastella G et al. (2015) A journey into a Mediterranean diet and type 2 diabetes: a systematic review with meta-analyses. BMJ Open 5, $\mathrm{e} 008222$.

7. Alvarez León EE, Henríquez P \& Serra-Majem L (2006) Mediterranean diet and metabolic syndrome: a cross-sectional study in the Canary Islands. Public Health Nutr 9, 1089-1098.

8. Scarmeas N, Stern Y, Tang M-X et al. (2006) Mediterranean diet and risk for Alzheimer's disease. Ann Neurol 59, 912-921.

9. Scarmeas N, Anastasiou CA \& Yannakoulia M (2018) Nutrition and prevention of cognitive impairment. Lancet Neurol 17, 1006-1015. 
10. Schwingshack1 L, Schwedhelm C, Galbete C et al. (2017) Adherence to Mediterranean diet and risk of cancer: An updated systematic review and meta-analysis. Nutrients $\mathbf{9}$, 1063.

11. Estruch R, Ros E, Salas-Salvadó J et al. (2013) Primary prevention of cardiovascular disease with a Mediterranean diet. N Engl J Med 368, 1279-1290.

12. Estruch R, Ros E, Salas-Salvadó J et al. (2018) Primary Prevention of Cardiovascular Disease with a Mediterranean Diet Supplemented with Extra-Virgin Olive Oil or Nuts. N Engl J Med. 387, e34.

13. Salas-Salvadó J, Bulló M, Babio N et al. (2011) Reduction in the Incidence of Type 2 Diabetes With the Mediterranean Diet: Results of the PREDIMED-Reus nutrition intervention randomized trial. Diabetes Care 34, 14-19.

14. Toledo E, Salas-Salvadó J, Donat-Vargas C et al. (2015) Mediterranean Diet and Invasive Breast Cancer Risk Among Women at High Cardiovascular Risk in the PREDIMED Trial: A Randomized Clinical Trial. JAMA Intern Med 175, 1752-1760.

15. Tipton KD (2015) Nutritional Support for Exercise-Induced Injuries. Sports Med. 45, 93-104.

16. Thomas DT, Erdman KA \& Burke LM (2016) American College of Sports Medicine Joint Position Statement. Nutrition and Athletic Performance. Med Sci Sports Exerc 48, 543-568.

17. Jeukendrup A \& Gleeson M (2010) Sport Nutrition - 2nd Ed. Champaign, IL: Human Kinetics Publishers.

18. Rehrer NJ, Hellemans IJ, Rolleston AK et al. (2010) Energy intake and expenditure during a 6-day cycling stage race. Scand J Med Sci Sports 20, 609-618. 
19. Baker ME, DeCesare KN, Johnson A et al. (2019) Short-Term Mediterranean Diet Improves Endurance Exercise Performance: A Randomized-Sequence Crossover Trial. J Am Coll Nutr 38, 597-605.

20. Lansley KE, Winyard PG, Bailey SJ et al. (2011) Acute Dietary Nitrate Supplementation Improves Cycling Time Trial Performance: Med Sci Sports Exerc 43, $1125-1131$

21. Shannon OM, Barlow MJ, Duckworth L et al. (2017) Dietary nitrate supplementation enhances short but not longer duration running time-trial performance. Eur J Appl Physiol 117, 775-785.

22. Porcelli S, Pugliese L, Rejc E et al. (2016) Effects of a Short-Term High-Nitrate Diet on Exercise Performance. Nutrients 8, 534.

23. Shannon OM, Easton C, Shepherd AI et al. (2021) Dietary nitrate and population health: a narrative review of the translational potential of existing laboratory studies. BMC Sports Sci. Med Rehabil 13, 65.

24. Lewis EJH, Radonic PW, Wolever TMS et al. (2015) 21 days of mammalian omega-3 fatty acid supplementation improves aspects of neuromuscular function and performance in male athletes compared to olive oil placebo. J Int Soc Sports Nutr 12, 28.

25. Cook MD, Myers SD, Blacker SD et al. (2015) New Zealand blackcurrant extract improves cycling performance and fat oxidation in cyclists. Eur J Appl Physiol 115, 2357-2365.

26. Keane KM, Bailey SJ, Vanhatalo A et al. (2018) Effects of montmorency tart cherry (L. Prunus Cerasus) consumption on nitric oxide biomarkers and exercise performance. Scand J Med Sci Sports 28, 1746-1756. 
27. Yi M, Fu J, Zhou L et al. (2014) The effect of almond consumption on elements of endurance exercise performance in trained athletes. J Int Soc Sports Nutr 11, 18.

28. Carr A, McGawley K, Govus A et al. (2019) Nutritional Intake in Elite Cross-Country Skiers During Two Days of Training and Competition. Int J Sport Nutr Exerc Metab 29, 273-281.

29. Burke LM, Hawley JA, Wong SHS et al. (2011) Carbohydrates for training and competition. J Sports Sci 29 Suppl 1, S17-27.

30. Scientific Advisory Committee on Nutrition (2015) Carbohydrates and Health. UK: TSO.

31. COMA (1991) Dietary Reference Values for Food Energy and Nutrients for the United Kingdom. UK: TSO.

32. Phillips SM \& Van Loon LJC (2011) Dietary protein for athletes: from requirements to optimum adaptation. J Sports Sci 29 Suppl 1, S29-38.

33. Broad EM \& Cox GR (2008) What is the optimal composition of an athlete's diet? Eur J Sport Sci 8, 57-65.

34. Davis C, Bryan J, Hodgson J et al. (2015) Definition of the Mediterranean Diet; A Literature Review. Nutrients 7, 9139-9153.

35. Karamanos B, Thanopoulou A, Angelico F et al. (2002) Nutritional habits in the Mediterranean Basin. The macronutrient composition of diet and its relation with the traditional Mediterranean diet. Multi-centre study of the Mediterranean Group for the Study of Diabetes (MGSD). Eur J Clin Nutr 56, 983-991.

36. Passariello CL, Marchionni S, Carcuro M et al. (2020) The Mediterranean Athlete's Nutrition: Are Protein Supplements Necessary? Nutrients 12, 3681. 
37. Shannon OM, Stephan BCM, Granic A et al. (2019) Mediterranean diet adherence and cognitive function in older UK adults: the European Prospective Investigation into Cancer and Nutrition-Norfolk (EPIC-Norfolk) Study. Am J Clin Nutr 110, 938-948.

38. Jackson MJ, Vasilaki A \& McArdle A (2016) Cellular mechanisms underlying oxidative stress in human exercise. Free Radic Biol Med 98, 13-17.

39. Powers SK, Deminice R, Ozdemir M et al. (2020) Exercise-induced oxidative stress: Friend or foe? J Sport Health Sci 9, 415-425.

40. Powers SK, Duarte J, Kavazis AN et al. (2010) Reactive oxygen species are signalling molecules for skeletal muscle adaptation. Exp Physiol 95, 1-9.

41. Pastor R \& Tur JA (2019) Antioxidant Supplementation and Adaptive Response to Training: A Systematic Review. Curr Pharm Des 25, 1889-1912.

42. Done AJ, Gage MJ, Nieto NC et al. (2016) Exercise-induced Nrf2-signaling is impaired in aging. Free Radic Biol Med 96, 130-138.

43. Place N, Ivarsson N, Venckunas T et al. (2015) Ryanodine receptor fragmentation and sarcoplasmic reticulum $\mathrm{Ca} 2+$ leak after one session of high-intensity interval exercise. Proc Natl Acad Sci USA. 112, 15492-15497.

44. Jones DP (2006) Redefining oxidative stress. Antioxid Redox Signal. 8, 1865-1879.

45. Radak Z, Chung HY \& Goto S (2005) Exercise and hormesis: oxidative stress-related adaptation for successful aging. Biogerontology 6, 71-75.

46. Margaritelis NV, Paschalis V, Theodorou AA et al. (2020) Antioxidant supplementation, redox deficiencies and exercise performance: A falsification design. Free Radic Biol Med 158, 44-52.

47. Barnard ND, Goldman DM, Loomis JF et al. (2019) Plant-Based Diets for Cardiovascular Safety and Performance in Endurance Sports. Nutrients 11, 130. 
48. Yavari A, Javadi M, Mirmiran P et al. (2015) Exercise-Induced Oxidative Stress and Dietary Antioxidants. Asian J Sports Med. 6.

49. Machefer G, Groussard C, Zouhal H et al. (2007) Nutritional and plasmatic antioxidant vitamins status of ultra endurance athletes. J Am Coll Nutr 26, 311-316.

50. Koivisto AE, Paulsen G, Paur I et al. (2018) Antioxidant-rich foods and response to altitude training: A randomized controlled trial in elite endurance athletes. Scand $J$ Med Sci Sports 28, 1982-1995.

51. Gomez-Cabrera M-C, Domenech E, Romagnoli M et al. (2008) Oral administration of vitamin $\mathrm{C}$ decreases muscle mitochondrial biogenesis and hampers training-induced adaptations in endurance performance. Am J Clin Nutr 87, 142-149.

52. Wehrlin JP, Marti B \& Hallén J (2016) Hemoglobin Mass and Aerobic Performance at Moderate Altitude in Elite Athletes. Adv Exp Med Biol 903, 357-374.

53. Kerksick CM, Wilborn CD, Roberts MD et al. (2018) ISSN exercise \& sports nutrition review update: research \& recommendations. J Int Soc Sports Nutr 15, 38.

54. Watson TA, Callister R, Taylor RD et al. (2005) Antioxidant restriction and oxidative stress in short-duration exhaustive exercise. Med Sci Sports Exerc 37, 63-71.

55. Schaffer S, Podstawa M, Visioli F et al. (2007) Hydroxytyrosol-rich olive mill wastewater extract protects brain cells in vitro and ex vivo. J Agric Food Chem 55, $5043-5049$.

56. Sun W, Wang X, Hou C et al. (2017) Oleuropein improves mitochondrial function to attenuate oxidative stress by activating the Nrf2 pathway in the hypothalamic paraventricular nucleus of spontaneously hypertensive rats. Neuropharmacology 113, $556-566$. 
937 57. Musumeci G, Maria Trovato F, Imbesi R et al. (2014) Effects of dietary extra-virgin olive oil on oxidative stress resulting from exhaustive exercise in rat skeletal muscle: a morphological study. Acta Histochem 116, 61-69.

58. Urquiaga I, Strobel P, Perez D et al. (2010) Mediterranean diet and red wine protect against oxidative damage in young volunteers. Atherosclerosis 211, 694-699.

59. Micallef M, Lexis L \& Lewandowski P (2007) Red wine consumption increases antioxidant status and decreases oxidative stress in the circulation of both young and old humans. Nutr $J$ 6, 27.

60. Fernández-Pachón MS, Berná G, Otaolaurruchi E et al. (2009) Changes in antioxidant endogenous enzymes (activity and gene expression levels) after repeated red wine intake. J Agric Food Chem 57, 6578-6583.

61. Estruch R, Sacanella E, Mota F et al. (2011) Moderate consumption of red wine, but not gin, decreases erythrocyte superoxide dismutase activity: A randomised cross-over trial. Nutr Metab Cardiovasc Dis 21, 46-53.

62. Noguer MA, Cerezo AB, Donoso Navarro E et al. (2012) Intake of alcohol-free red wine modulates antioxidant enzyme activities in a human intervention study. Pharmacol Res. 65, 609-614.

63. Billingsley HE \& Carbone S (2018) The antioxidant potential of the Mediterranean diet in patients at high cardiovascular risk: an in-depth review of the PREDIMED. Nutr Diabetes 8, 13.

64. Peake JM, Neubauer O, Della Gatta PA et al. (2016) Muscle damage and inflammation during recovery from exercise. J Appl Physiol 122, 559-570.

65. Pizza FX, Peterson JM, Baas JH et al. (2005) Neutrophils contribute to muscle injury and impair its resolution after lengthening contractions in mice. J Physiol 562, 899913. 
66. Yamada R, Himori K, Tatebayashi D et al. (2018) Preconditioning contractions prevent the delayed onset of myofibrillar dysfunction after damaging eccentric contractions. J Physiol 596, 4427-4442.

67. Bell P, Walshe I, Davison G et al. (2014) Montmorency Cherries Reduce the Oxidative Stress and Inflammatory Responses to Repeated Days High-Intensity Stochastic Cycling. Nutrients 6, 829-843.

68. Govus AD, Andersson EP, Shannon OM et al. (2018) Commercially available compression garments or electrical stimulation do not enhance recovery following a sprint competition in elite cross-country skiers. Eur J Sport Sci 18, 1299-1308.

69. Markworth JF, Maddipati KR \& Cameron-Smith D (2016) Emerging roles of proresolving lipid mediators in immunological and adaptive responses to exercise-induced muscle injury. Exerc Immunol Rev 22, 110-134.

70. Bueno AM, Pilgaard M, Hulme A et al. (2018) Injury prevalence across sports: a descriptive analysis on a representative sample of the Danish population. Inj Epidemiol. 5, 6.

71. Lin E, Kotani JG \& Lowry SF (1998) Nutritional modulation of immunity and the inflammatory response. Nutrition 14, 545-550.

72. Lisowska B, Kosson D \& Domaracka K (2018) Positives and negatives of nonsteroidal anti-inflammatory drugs in bone healing: the effects of these drugs on bone repair. Drug Des. Devel Ther 12, 1809-1814.

73. Ziltener J-L, Leal S \& Fournier P-E (2010) Non-steroidal anti-inflammatory drugs for athletes: An update. Ann Phys Rehabil Med 53, 278-288.

74. Arpón A, Riezu-Boj JI, Milagro FI et al. (2016) Adherence to Mediterranean diet is associated with methylation changes in inflammation-related genes in peripheral blood cells. J Physiol Biochem 73, 445-455. 
75. Perez-Martinez P, Lopez-Miranda J, Blanco-Colio L et al. (2007) The chronic intake of a Mediterranean diet enriched in virgin olive oil, decreases nuclear transcription factor kappaB activation in peripheral blood mononuclear cells from healthy men. Atherosclerosis 194, e141-146.

76. Jouris KB, McDaniel JL \& Weiss EP (2011) The Effect of Omega-3 Fatty Acid Supplementation on the Inflammatory Response to eccentric strength exercise. $J$ Sports Sci Med 10, 432-438.

77. McAnulty LS, Nieman DC, Dumke CL et al. (2011) Effect of blueberry ingestion on natural killer cell counts, oxidative stress, and inflammation prior to and after $2.5 \mathrm{~h}$ of running. Appl Physiol Nutr Metab 36, 976-984.

78. Howatson G, McHugh MP, Hill JA et al. (2010) Influence of tart cherry juice on indices of recovery following marathon running: Cherry juice supplementation and Marathon running. Scand J Med Sci Sports 20, 843-852.

79. Shannon OM, Mendes I, Köchl C et al. (2020) Mediterranean Diet Increases Endothelial Function in Adults: A Systematic Review and Meta-Analysis of Randomized Controlled Trials. J Nutr 150, 1151-1159.

80. Malmir H, Saneei P, Larijani B et al. (2018) Adherence to Mediterranean diet in relation to bone mineral density and risk of fracture: a systematic review and metaanalysis of observational studies. Eur J Nutr 57, 2147-2160.

81. Ryan-Moore E, Mavrommatis Y \& Waldron M (2020) Systematic Review and MetaAnalysis of Candidate Gene Association Studies With Fracture Risk in Physically Active Participants. Front Genet 11, 551.

82. Rizzone KH, Ackerman KE, Roos KG et al. (2017) The Epidemiology of Stress Fractures in Collegiate Student-Athletes, 2004-2005 Through 2013-2014 Academic Years. J Athl Train 52, 966-975. 
1012 83. Nagle KB \& Brooks MA (2011) A Systematic Review of Bone Health in Cyclists.

1013

1014

1015

1016

1017

1018

1019

1020

1021

1022

1023

1024

1025

1026

1027

1028

1029

1030

1031

1032

1033

1034

1035

1036 Sports Health 3, 235-243.

84. Liu H, Huang H, Li B et al. (2014) Olive oil in the prevention and treatment of osteoporosis after artificial menopause. Clin Interv Aging 9, 2087-2095.

85. Fernández-Real JM, Bulló M, Moreno-Navarrete JM et al. (2012) A Mediterranean diet enriched with olive oil is associated with higher serum total osteocalcin levels in elderly men at high cardiovascular risk. J Clin Endocrinol Metab. 97, 3792-3798.

86. Zupo R, Lampignano L, Lattanzio A et al. (2020) Association between adherence to the Mediterranean Diet and circulating Vitamin D levels. Int J Food Sci Nutr 71, 884890.

87. Seiquer I, Mesías M, Hoyos AM et al. (2008) A Mediterranean dietary style improves calcium utilization in healthy male adolescents. $J$ Am Coll Nutr 27, 454-462.

88. You J-S, Park M-N, Song W et al. (2010) Dietary fish oil alleviates soleus atrophy during immobilization in association with Akt signaling to p70s6k and E3 ubiquitin ligases in rats. Appl Physiol Nutr Metab 35, 310-318.

89. Smith GI, Atherton P, Reeds DN et al. (2011) Omega-3 polyunsaturated fatty acids augment the muscle protein anabolic response to hyperinsulinaemiahyperaminoacidaemia in healthy young and middle-aged men and women. Clin Sci (Lond) 121, 267-278.

90. Salberg S, Yamakawa G, Christensen J et al. (2017) Assessment of a nutritional supplement containing resveratrol, prebiotic fiber, and omega-3 fatty acids for the prevention and treatment of mild traumatic brain injury in rats. Neuroscience $\mathbf{3 6 5}$, $146-157$.

91. Wang T, Van KC, Gavitt BJ et al. (2013) Effect of fish oil supplementation in a rat model of multiple mild traumatic brain injuries. Restor Neurol Neurosci 31, 647-659. 
92. Albina JE, Gladden P \& Walsh WR (1993) Detrimental effects of an omega-3 fatty acid-enriched diet on wound healing. JPEN J Parenter Enteral Nutr 17, 519-521.

93. Simpson RJ, Campbell JP, Gleeson M et al. (2020) Can exercise affect immune function to increase susceptibility to infection? Exerc Immunol Rev. 26, 8-22.

94. Campbell JP \& Turner JE (2018) Debunking the Myth of Exercise-Induced Immune Suppression: Redefining the Impact of Exercise on Immunological Health Across the Lifespan. Front. Immunol. 9, 648.

95. Spence L, Brown WJ, Pyne DB et al. (2007) Incidence, etiology, and symptomatology of upper respiratory illness in elite athletes. Med Sci Sports Exerc 39, 577-586.

96. Valtonen M, Waris M, Vuorinen T et al. (2019) Common cold in Team Finland during 2018 Winter Olympic Games (PyeongChang): epidemiology, diagnosis including molecular point-of-care testing (POCT) and treatment. Br J Sports Med 53, 10931098.

97. Engebretsen L, Steffen K, Alonso JM et al. (2010) Sports injuries and illnesses during the Winter Olympic Games 2010. Br J Sports Med 44, 772-780.

98. Engebretsen L, Soligard T, Steffen K et al. (2013) Sports injuries and illnesses during the London Summer Olympic Games 2012. Br J Sports Med 47, 407-414.

99. Raysmith BP \& Drew MK (2016) Performance success or failure is influenced by weeks lost to injury and illness in elite Australian track and field athletes: A 5-year prospective study. J Sci Med Sport 19, 778-783.

100. Childs CE, Calder PC \& Miles EA (2019) Diet and Immune Function. Nutrients 11, 1933.

101. Gray MS, Wang HE, Martin KD et al. (2018) Adherence to Mediterranean-style diet and risk of sepsis in the REasons for Geographic and Racial Differences in Stroke (REGARDS) cohort. Br J Nutr 120, 1415-1421. 
102. Calatayud FM, Calatayud B, Gallego JG et al. (2017) Effects of Mediterranean diet in patients with recurring colds and frequent complications. Allergol Immunopathol (Madr) 45, 417-424.

103. Calder PC, Carr AC, Gombart AF et al. (2020) Optimal Nutritional Status for a WellFunctioning Immune System Is an Important Factor to Protect against Viral Infections. Nutrients 12, 1181.

104. Basil MC \& Levy BD (2016) Specialized pro-resolving mediators: endogenous regulators of infection and inflammation. Nat Rev Immunol 16, 51-67.

105. Da Boit M, Mastalurova I, Brazaite G et al. (2015) The Effect of Krill Oil Supplementation on Exercise Performance and Markers of Immune Function. PLoS ONE 10, e0139174.

106. Gray P, Gabriel B, Thies F et al. (2012) Fish oil supplementation augments postexercise immune function in young males. Brain Behav Immun 26, 1265-1272.

107. Rincón-Cervera MÁ, González-Barriga V, Romero J et al. (2020) Quantification and Distribution of Omega-3 Fatty Acids in South Pacific Fish and Shellfish Species. Foods 9, 233.

108. Medina-Remón A, Tresserra-Rimbau A, Pons A et al. (2015) Effects of total dietary polyphenols on plasma nitric oxide and blood pressure in a high cardiovascular risk cohort. The PREDIMED randomized trial. Nutr Metab Cardiovasc Dis 25, 60-67.

109. Campagna M \& Rivas C (2010) Antiviral activity of resveratrol. Biochem Soc Trans $38,50-53$.

110. Paulo L, Ferreira S, Gallardo E et al. (2010) Antimicrobial activity and effects of resveratrol on human pathogenic bacteria. World J Microbiol Biotechnol 26, $1533-$ 1538. 
1086 111. Paraiso IL, Revel JS \& Stevens JF (2020) Potential use of polyphenols in the battle against COVID-19. Curr Opin Food Sci 32, 149-155.

112. Droebner K, Ehrhardt C, Poetter A et al. (2007) CYSTUS052, a polyphenol-rich plant extract, exerts anti-influenza virus activity in mice. Antiviral Res. 76, 1-10.

113. Ahmed M, Henson DA, Sanderson MC et al. (2015) Rhodiola rosea Exerts Antiviral Activity in Athletes Following a Competitive Marathon Race. Front Nutr 2, 24.

114. Lackermair K, Scherr J, Waidhauser G et al. (2017) Influence of polyphenol-rich diet on exercise-induced immunomodulation in male endurance athletes. Appl Physiol Nutr Metab 42, 1023-1030.

115. Nieman DC, Henson DA, Gross SJ et al. (2007) Quercetin reduces illness but not 1096 immune perturbations after intensive exercise. Med Sci Sports Exerc 39, 1561-1569.

1097

1098

1099

116. Scherr J, Nieman DC, Schuster T et al. (2012) Nonalcoholic beer reduces inflammation and incidence of respiratory tract illness. Med Sci Sports Exerc 44, 18-

117. Nieman DC (2010) Quercetin's bioactive effects in human athletes. Curr Top Nutraceutical Res 8, 33-43.

118. Bermon S, Castell LM, Calder PC et al. (2017) Consensus Statement Immunonutrition and Exercise. Exer Immunol Rev 23, 8-50.

119. Dabeek WM \& Marra MV (2019) Dietary Quercetin and Kaempferol: Bioavailability and Potential Cardiovascular-Related Bioactivity in Humans. Nutrients 11, 2288.

1106 120. Ouchi E, Niu K, Kobayashi Y et al. (2012) Frequent alcohol drinking is associated 1107 with lower prevalence of self-reported common cold: a retrospective study. $B M C$ Public Health 12, 987. 
1109 121. Naci H \& Ioannidis JPA (2015) Comparative effectiveness of exercise and drug

1110 interventions on mortality outcomes: metaepidemiological study. Br J Sports Med 49,

$1111 \quad 1414-1422$.

1112 122. Merghani A, Maestrini V, Rosmini S et al. (2017) Prevalence of Subclinical Coronary 1113 Artery Disease in Masters Endurance Athletes With a Low Atherosclerotic Risk $1114 \quad$ Profile. Circulation 136, 126-137.

1115 123. Schwartz RS, Kraus SM, Schwartz JG et al. (2014) Increased Coronary Artery Plaque Volume Among Male Marathon Runners. Mo Med 111, 89-94.

124. Fernández JM, Rosado-Álvarez D, Da Silva Grigoletto ME et al. (2012) Moderate-tohigh-intensity training and a hypocaloric Mediterranean diet enhance endothelial progenitor cells and fitness in subjects with the metabolic syndrome. Clin Sci 123,

125. Cowell OR, Mistry N, Deighton K et al. (2020) Effects of a Mediterranean diet on blood pressure: a systematic review and meta-analysis of randomized controlled trials and observational studies. J Hypertens 39, 729-739.

1124 126. Shannon OM, Duckworth L, Barlow MJ et al. (2017) Effects of Dietary Nitrate Supplementation on Physiological Responses, Cognitive Function, and Exercise Performance at Moderate and Very-High Simulated Altitude. Front Physiol. 8, 401.

127. Brisswalter J, Collardeau M \& René A (2002) Effects of acute physical exercise characteristics on cognitive performance. Sports Med 32, 555-566.

1129 128. Meeusen R (2014) Exercise, Nutrition and the Brain. Sports Med. 44, 47-56.

1130 129. Petersson SD \& Philippou E (2016) Mediterranean Diet, Cognitive Function, and Dementia: A Systematic Review of the Evidence. Adv Nutr 7, 889-904. 
130. Anastasiou CA, Yannakoulia M, Kontogianni MD et al. (2018) Mediterranean Lifestyle in Relation to Cognitive Health: Results from the HELIAD Study. Nutrients $10,1557$.

131. Martínez-Lapiscina EH, Clavero P, Toledo E et al. (2013) Mediterranean diet improves cognition: the PREDIMED-NAVARRA randomised trial. $J$ Neurol Neurosurg Psychiatry 84, 1318-25

132. Martínez-Lapiscina EH, Galbete C, Corella D et al. (2014) Genotype patterns at CLU, CR1, PICALM and APOE, cognition and Mediterranean diet: the PREDIMEDNAVARRA trial. Genes Nutr. 9, 393.

133. Valls-Pedret C, Sala-Vila A, Serra-Mir M et al. (2015) Mediterranean Diet and AgeRelated Cognitive Decline: A Randomized Clinical Trial. JAMA Intern Med 175, $1094-1103$.

134. Knight A, Bryan J, Wilson C et al. (2016) The Mediterranean Diet and Cognitive Function among Healthy Older Adults in a 6-Month Randomised Controlled Trial: The MedLey Study. Nutrients 8, 579.

135. Thompson C, Wylie LJ, Fulford J et al. (2015) Dietary nitrate improves sprint performance and cognitive function during prolonged intermittent exercise. Eur J Appl Physiol 115, 1825-34

136. Thompson C, Vanhatalo A, Jell H et al. (2016) Dietary nitrate supplementation improves sprint and high-intensity intermittent running performance. Nitric Oxide, $\mathbf{3 0}$, $55-61$

137. Philip P, Sagaspe P, Taillard J et al. (2019) Acute Intake of a Grape and Blueberry Polyphenol-Rich Extract Ameliorates Cognitive Performance in Healthy Young Adults During a Sustained Cognitive Effort. Antioxidants 8, 650. 
138. Shannon OM, Stephan BCM, Minihane A-M et al. (2018) Nitric oxide boosting effects of the Mediterranean diet: A potential mechanism of action. J Gerontol A Biol Sci Med Sci 73, 902-904.

139. McMillan L, Owen L, Kras M et al. (2011) Behavioural effects of a 10-day Mediterranean diet. Results from a pilot study evaluating mood and cognitive performance. Appetite 56, 143-147.

140. Impey SG, Hearris MA, Hammond KM et al. (2018) Fuel for the Work Required: A Theoretical Framework for Carbohydrate Periodization and the Glycogen Threshold Hypothesis. Sports Med 48, 1031-1048.

141. Jäger R, Kerksick CM, Campbell BI et al. (2017) International Society of Sports Nutrition Position Stand: protein and exercise. J Int Soc Sports Nutr 14, 20.

142. Aragon AA \& Schoenfeld BJ (2013) Nutrient timing revisited: is there a post-exercise anabolic window? J Int Soc Sports Nutr. 10, 5.

143. Breen L \& Churchward-Venne TA (2012) Leucine: a nutrient 'trigger' for muscle anabolism, but what more? J Physiol 590, 2065-2066.

144. Tong TYN, Wareham NJ, Khaw K-T et al. (2016) Prospective association of the Mediterranean diet with cardiovascular disease incidence and mortality and its population impact in a non-Mediterranean population: the EPIC-Norfolk study. BMC Med 14, 135.

145. Malik VS, Schulze MB \& Hu FB (2006) Intake of sugar-sweetened beverages and weight gain: a systematic review. Am J Clin Nutr 84, 274-288.

146. Vartanian LR, Schwartz MB \& Brownell KD (2007) Effects of soft drink consumption on nutrition and health: a systematic review and meta-analysis. Am J Public Health 97, $667-675$. 
147. Fung TT, Malik V, Rexrode KM et al. (2009) Sweetened beverage consumption and risk of coronary heart disease in women. Am J Clin Nutr 89, 1037-1042.

148. Jeukendrup AE (2004) Carbohydrate intake during exercise and performance. Nutrition 20, 669-677.

149. McGawley K, Shannon O \& Betts J (2012) Ingesting a high-dose carbohydrate solution during the cycle section of a simulated Olympic-distance triathlon improves subsequent run performance. Appl Physiol Nutr Metab 37, 664-671.

150. Ivy JL, Katz AL, Cutler CL et al. (1988) Muscle glycogen synthesis after exercise: effect of time of carbohydrate ingestion. J Appl Physiol 64, 1480-1485.

151. Griffiths A, Deighton K, Shannon OM et al. (2019) Substrate oxidation and the influence of breakfast in normobaric hypoxia and normoxia. Eur J Appl Physiol 119, $1909-1920$.

152. Griffiths A, Deighton K, Boos CJ et al. (2021) Carbohydrate Supplementation and the Influence of Breakfast on Fuel Use in Hypoxia. Med Sci Sports Exerc 53, 785-795.

153. Stellingwerff T \& Cox GR (2014) Systematic review: Carbohydrate supplementation on exercise performance or capacity of varying durations. Appl Physiol Nutr Metab 39, $998-1011$.

154. Nieman DC \& Wentz LM (2019) The compelling link between physical activity and the body's defense system. J Sport Health Sci 8, 201-217.

155. Barnes MJ (2014) Alcohol: Impact on Sports Performance and Recovery in Male Athletes. Sports Med 44, 909-919.

156. GBD 2016 Alcohol Collaborators (2018) Alcohol use and burden for 195 countries and territories, 1990-2016: a systematic analysis for the Global Burden of Disease Study 2016. Lancet 392, 1015-1035. 
157. Moss HB (2013) The impact of alcohol on society: a brief overview. Soc. Work Public Health 28, 175-177.

158. Lamuela-Raventós RM \& de la Torre-Boronat MC (1999) Beneficial effects of white wines. Drugs Exp Clin Res 25, 121-124.

159. Gago B, Lundberg JO, Barbosa RM et al. (2007) Red wine-dependent reduction of nitrite to nitric oxide in the stomach. Free Radic Biol Med. 43, 1233-1242.

160. La Verde M, Mulè S, Zappalà G et al. (2018) Higher adherence to the Mediterranean diet is inversely associated with having hypertension: is low salt intake a mediating factor? Int J Food Sci Nutr 69, 235-244.

161. Anastasiou CA, Kavouras SA, Arnaoutis G et al. (2009) Sodium Replacement and

165. Mentella MC, Scaldaferri F, Ricci C et al. (2019) Cancer and Mediterranean Diet: A Review. Nutrients 11, 2059. 
166. de Oliveira EP, Burini RC \& Jeukendrup A (2014) Gastrointestinal Complaints During Exercise: Prevalence, Etiology, and Nutritional Recommendations. Sports Med 44, 7985.

167. Rehrer NJ, van Kemenade M, Meester W et al. (1992) Gastrointestinal complaints in relation to dietary intake in triathletes. Int J Sport Nutr 2, 48-59.

168. Bentley MRN, Patterson LB, Mitchell N et al. (2021) Athlete perspectives on the enablers and barriers to nutritional adherence in high-performance sport. Psychol Sport Exerc 52, 101831.

169. Baranauskas M, Stukas R, Tubelis L et al. (2015) Nutritional habits among highperformance endurance athletes. Medicina 51, 351-362.

170. Gillen JB, Trommelen J, Wardenaar FC et al. (2017) Dietary Protein Intake and Distribution Patterns of Well-Trained Dutch Athletes. Int J Sport Nutr Exerc Metab 27, $105-114$.

171. Burke LM, Slater G, Broad EM et al. (2003) Eating patterns and meal frequency of elite Australian athletes. Int J Sport Nutr Exerc Metab 13, 521-538.

172. Horvath PJ, Eagen CK, Ryer-Calvin SD et al. (2000) The effects of varying dietary fat on the nutrient intake in male and female runners. $J$ Am Coll Nutr 19, 42-51.

173. Jonnalagadda SS, Bernadot D \& Nelson M (1998) Energy and nutrient intakes of the United States National Women's Artistic Gymnastics Team. Int J Sport Nutr 8, 331344.

174. Hawley JA, Dennis SC, Lindsay FH et al. (1995) Nutritional practices of athletes: Are they sub-optimal? J Sports Sci 13, S75-S81.

175. Close GL, Sale C, Baar K et al. (2019) Nutrition for the Prevention and Treatment of Injuries in Track and Field Athletes. Int J Sport Nutr Exerc Metab 29, 189-197. 
176. Muros JJ \& Zabala M (2018) Differences in Mediterranean Diet Adherence between Cyclists and Triathletes in a Sample of Spanish Athletes. Nutrients 10, 1480.

177. Rubio-Arias JÁ, Ramos Campo DJ, Ruiloba Nuñez JM et al. (2015) Adherence to a mediterranean diet and sport performance in a elite female athletes futsal population. Nutr Hosp 31, 2276-2282.

178. Mayolas-Pi C, Munguia-Izquierdo D, Peñarrubia-Lozano C et al. (2017) Adherence to the Mediterranean diet in inactive adults, indoor cycling practitioners and amateur cyclists. Nutr Hosp 35, 131-139.

179. Alacid F, Vaquero-Cristóbal R, Sánchez-Pato A et al. (2014) Habit based consumptions in the mediterranean diet and the relationship with anthropometric parameters in young female kayakers. Nutr Hosp 29, 121-127.

180. Sánchez-Benito JL, Sánchez-Soriano E \& Ginart Suárez J (2009) Assessment of the Mediterranean Diet Adequacy Index of a collective of young cyclists. Nutr Hosp 24, $77-86$.

181. León-Muñoz LM, Guallar-Castillón P, Graciani A et al. (2012) Adherence to the Mediterranean diet pattern has declined in Spanish adults. J Nutr 142, 1843-1850.

182. Hull MV, Jagim AR, Oliver JM et al. (2016) Gender differences and access to a sports dietitian influence dietary habits of collegiate athletes. J Int Soc Sports Nutr 13, 38.

183. Spronk I, Heaney SE, Prvan T et al. (2015) Relationship Between General Nutrition Knowledge and Dietary Quality in Elite Athletes. Int J Sport Nutr Exerc Metab 25, $243-251$.

184. Heaney S, O’Connor H, Michael S et al. (2011) Nutrition knowledge in athletes: a systematic review. Int J Sport Nutr Exerc Metab 21, 248-261. 
1276

1277

1278

1279

1280

1281

1282

1283 